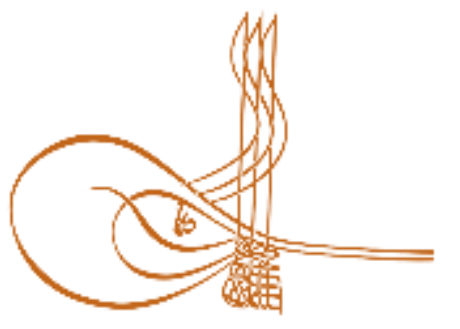

www.turkishstudies.net/turkishstudies
Turkish Studies

eISSN: $1308-2140$

Research Article / Araştırma Makalesi

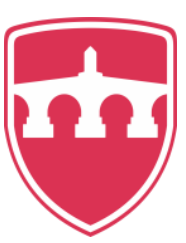

INTERNATIONAL

BALKAN

UNIVERSITY

Sponsored by IBU

\title{
Yeni Miras Kanununun Arazi Toplulaştırmasına Olası Etkilerinin İncelenmesi Üzerine Bir Çalışma
}

\author{
A Study On The Possible Effects Of The New Inheritance Law On Land Consolidation
}

\author{
Şerife Tülin Akkaya Aslan* - Merve Küçük**
}

\begin{abstract}
Land consolidation aims at combining land and arranging land forms to eliminate land fragmentation and parcel scattering. Along with these regulations, land consolidation is the works that provide many infrastructure services such as road, irrigation network, drainage and leveling to agricultural lands. With the land consolidation efforts, it is aimed to bring together the fragmented and scattered parcels to form larger parcels. Elimination of land fragmentation is one of the most important objectives of land consolidation. Turkey and the world in many countries, one of the leading causes of the fragmentation of agricultural land fragmentation by inheritance. In order to prevent the fragmentation of agricultural lands, many legal regulations have been implemented in our country from past to present. The latest regulation is the Law "Soil Conservation and Land Use No: 6537" which came into force in 2014. Within the scope of the amendments made with this regulation, minimum agricultural land size and sufficient income agricultural land sizes and economic integrity concepts are introduced and some restrictions on the division of agricultural land comes. In this study, by examining the new inheritance law in this context, it is tried to determine the possible effects of land consolidation and land fragmentation. In this study, land consolidation data of Çankırı-Kızılırmak-Karamürsel, Denizli-Tavas-Altınova, Konya-Karapınar- Karakışla, Bursa-Yenişehir- Yazılı and Çiçeközü villages were used. Land consolidation in Karamürsel, Altınova and Karakışla was carried out before 2014, while Yazılı and Çiçeközü were implemented after 2014.
\end{abstract}

Structured Abstract: The main purpose of land consolidation is to reduce land fragmentation and eliminate parcel scattering. Land consolidation aims to form larger parcels by bringing together parcels belonging to an agricultural enterprise. Reducing land fragmentation is one of the most important objectives of land consolidation. In Turkey and many countries, the heritage is one of the leading factors that cause fragmentation of agricultural land. Turkey has also carried out many regulations in order to prevent fragmentation of

\footnotetext{
${ }^{*}$ Doç. Dr., Uludağ Üniversitesi, Ziraat Fakültesi, Biyosistem Mühendisliği Bölümü Assoc. Prof. Dr., Bursa Uludag University Faculty of Agriculture 
agricultural land. The latest regulation is the Law "Soil Conservation and Land Use No: 6537" which came into force in 2014. Within the scope of the amendments made with this regulation, minimum agricultural land size and sufficient income agricultural land sizes and economic integrity concepts and restrictions on the division of agricultural land and agricultural enterprises are introduced. Minimum agricultural land size is defined as the smallest agricultural parcel size determined by the Ministry, which is the limit that cannot be subdivided. The size of agricultural land with sufficient income means that the size of the land that can be generated in order to provide for an average family. Economic integrity refers to the lands determined by the Ministry where more than one agricultural land owned by the same person is operated interdependently to add economic value to agricultural production activity. It is assumed that some of these definitions introduced by this law will have some negative effects on the consolidation of parcels during land consolidation studies.

In this study, by examining the new inheritance law in this context, it is tried to determine the possible effects of land consolidation and land fragmentation. In the study, land consolidation data of ÇankırıKızılırmak-Karamürsel, Denizli-Tavas-Altınova, Konya-Karapınar- Karakışla, Bursa-Yenişehir- Yazılı and Çiçeközü villages were used. Land consolidation in Karamürsel, Altınova and Karakışla was carried out before 2014, while Yazılı and Çiçeközü were implemented after 2014.

The data related to the land consolidation studies were obtained from the related institutions. In order to examine the legal situation related to the new inheritance law, relevant laws, regulations, application instructions and scientific researches were used. In this study, minimum agricultural land size and sufficient income agricultural land size and economic integrity concepts are examined. The changes of these three concepts in the villages identified as pre- and post- land consolidation areas were tried to be revealed. Since land consolidation areas in this study are absolute agricultural land, the minimum agricultural land size taken into consideration in the study is 0.2 hektar. Since the study areas are cultivated agricultural land, it has been used for economic integrity at 0.1 hektar according to related The Law.

Since the number of holdings in the study areas does not change before and after the land consolidation, the current land consolidation studies have no positive or negative impact on the size of the land with sufficient income. In this case, efforts should be made to increase the size of the enterprise during land consolidation.

It was found that the number of parcels with minimum land size increased in Karamürsel and Altınova and decrease in Karakışla. There is no change in the number of parcels with minimum land size in Çiçeközü and Yazilı. The main purpose of the land consolidation studies should be to increase the size of the parcel by combining the parcels owned by the enterprises as much as possible. The land consolidation regulations also do not provide any foresight. The minimum agricultural land size determined by law should be the target for the new parcel sizes to be created in land consolidation.

In the study, when the enterprises were examined in terms of economic integrity, the number of enterprises having economic integrity in Konya- Karapınar- Karakışla decreased while the number of Karamürsel and Altınova were increased. No significant increase was observed in the number of enterprises with economic integrity in Çiçeközü and Yazıll. Landowners will not want combine parcels which are over 0.10 hektar but lower than economic integrity. Because they cannot sell their this parcels separetely if they want. There is no regulation in existing land consolidation laws that prevents this. In fact, land consolidation rates that are not very high in the country will decrease further with the awareness of the law by the land holdings. In this context, with the reorganization of the laws and regulations related to the land consolidation, the new parcels to be formed should be regulated in such a way as to create economic integrity if the enterprise size is sufficient. In order to increase the size of agricultural holdings, this law should be put into effect as soon as possible and it should be ensured that the works to ensure the transfer/leasing of farmed land that is not living in rural areas to agricultural enterprises are carried out together with the land consolidation.

Keywords: Land fragmentation, Minimum agricultural land size, Agricultural land size with sufficient income, Economic integrity

Öz: Arazi toplulaştırması, arazi parçalılığının ve parsel dağınıklığının giderilmesi amacıyla arazilerin birleştirilmesi ve arazi şekillerinin düzenlenmesini amaçlar. Bu düzenlemelerle birlikte arazi toplulaştırması tarım arazilerine yol, sulama şebekesi, drenaj, tesviye başta olmak üzere birçok alt yapı hizmetini sağlamaktadır. Toplulaştırma çalışmaları ile parçalı ve dağınık parsellerin bir araya getirilmesi ile daha büyük

Turkish Studies, 15(1) 
parsellerin oluşturulması amaçlanmaktadır. Arazi parçalılı̆̆ının giderilmesi, arazi toplulaştırmasının en önemli hedeflerden biridir. Türkiye'de ve dünyanın birçok ülkesinde tarımsal arazilerin bu kadar fazla parçalanmasının nedenlerinin en başında miras yoluyla parçalanma gelmektedir. Tarımsal arazilerin parçalanmasını önlenmek amacıyla ülkemizde geçmişten bugüne pek çok yasal düzenleme uygulanmıştır. Tarım arazilerinde parçalanmayı önlemeye yönelik yapılan son yasal düzenleme, 2014 yılında "6537 sayılı Toprak Koruma ve Arazi Kullanımı Kanununda Değişiklik Yapılması Hakkında Kanun” ile yürürlüğe girmiştir. 6537 sayılı kanun ile yapılan değişiklikler kapsamında "asgari tarımsal arazi büyüklüğü" ve "yeterli gelirli tarımsal arazi büyüklüğü” ve "ekonomik bütünlük” kavramları tanımlanmış ve tarımsal arazilerin ve tarımsal işletmelerin bölünmesiyle ilgili bir dizi kısıtlamalar getirilmiştir. Bu çalışmada, yürürlüğe giren yeni miras kanununu bu bağlamda inceleyerek, arazi toplulaştırması çalışmaları esnasında arazi parçalanmasına olası etkileri belirlenmeye çalışılmıştır. Çalışmada Çankırı - Kızılırmak - Karamürsel, Denizli - Tavas - Altınova, KonyaKarapınar - Karakışla, Bursa - Yenişehir - Yazılı ve Çiçeközü köylerinin arazi toplulaştırma verileri kullanılmıştır. Karamürsel, Altınova ve Karakışla'da arazi toplulaştırması 2014'ten önce, Yazılı ve Çiçeközü' de 2014 'ten sonra uygulanmıştır.

Anahtar Kelimeler: Arazi parçalılı̆̆ı, Asgari tarımsal arazi büyüklüğü, Yeter gelirli tarımsal arazi büyüklüğü, Ekonomik bütünlük

\section{Giriş}

Arazi parçalılığı; tarımsal işletmeye ait arazilerin küçük parçalar halinde dağılmış olma durumu olarak tanımlanmaktadır (King ve Burton, 1982). Parçalanmanın devam etmesi ve parsellerin küçülerek parsel sayısında artış olması arazilerin ekonomik olarak işletilmesini engelledeiği gibi ve araziden alaınan ürünün verimliliğini de olumsuz etkilemektedir (Jha ve ark., 2005; Lerman, 2005; Janus ve ark., 2016; Niroula ve Thapa, 2005; Sayın ve ark., 2017). Arazi parçalılığı ülkemizde olduğu gibi tüm dünya da görülen oldukça yaygın bir olgudur (Niroula ve Thapa, 2005; Nguyen ve ark., 1996; Wan ve Cheng, 2001; Shuhao, 2005; Ntihinyurwa ve ark. 2019; Colombo ve Perujo-Villanueva 2019; Demetriou 2014; Yaslıoğlu ve ark., 2009; Akkaya Aslan ve ark., 2007).

Arazi parçalanmasının nedenleri ülkeden ülkeye hatta bölgeden bölgeye değişmekle birlikte dört ana etkileyici faktör üzerinde durulmaktadır: miras, nüfus artışı, arazi piyasaları ve tarihi/kültürel bakış açılarıdır (King ve Burton, 1982; Bentley, 1987; Niroula ve Thapa , 2005; Tan ve ark., 2006; Van Hung ve ark., 2007).

Türkiye'de tarım arazilerinin çok parçalı olmasının en temel nedenleri arasında ilk sırayı miras yoluyla oluşan parçalanmalar almaktadır. Kırsal alana götürülen yatırımlardan ve yapılan tarımsal yeniliklerden beklenen faydanın sağlanması için öncelikle tarımsal alt yapı ile ilgili sorunların çözülmesi gerekmektedir. Arazi toplulaştırması arazi parçalılığı sorunu yaşanan ülkelerde, bu sorunu çözmek için son birkaç yüzyıldır uygulanan önemli bir uygulama olup, kırsal reformun ve kalkınmanın da önemli bir aracı durumundadır (Crecente ve ark., 2002; Derlich, 2002; Van Dijk, 2003; Thomas, 2004; Van Dijk, 2007; Sklenicka, 2006; Thomas, 2006; Yaslığlu ve ark., 2008, 2009; Arici ve Akkaya Aslan, 2014; Luo ve Timothy 2017).

Tarımsal arazilerde miras hukuku ile ilgili ilk yasal düzenleme 1926 yılındaki Medeni Kanundur. 2001 yılında, 4721 Sayılı Kanun ile tarımsal araziler ile ilgili miras kısımları (659-668. Maddeleri) yeniden düzenlenmiştir. Ancak bu düzenlemeler tarımsal arazilerin parçalanmasını engellemekte yetersiz kaldığı için, 2005 yılında, "5403 Sayılı Toprak Koruma ve Arazi Kullanımı Kanunu" yürürlüğe konulmuştur. Yapılan bu düzenlemenin de tarım arazilerinin miras ve satış yoluyla parçalanarak küçülmesine engel olamadığı gözlemlenmiş ve Kanun'un konuya ilişkin temel hüküm niteliğindeki 8. maddesi, 2007 tarihinde, "5578 sayılı Toprak Koruma ve Arazi Kullanımı Kanununda Değişiklik Yapılması Hakkında Kanun"la önemli ölçüde değiştirilmiştir. Günümüzde toplulaştırma çalışmalarına hız verilirken bir yandan miras yolu ile hisselilik artmaya devam etmekte olduğundan 5403 sayılı kanunda; 15 Mayıs 2014 tarih ve 29001 sayılı resmi gazetede yayınlanan 
"6537 sayı11 30.04.2014 tarihli Toprak Koruma Ve Arazi Kullanımı Kanununda Değişiklik Yapılması Hakkında Kanun" ile tarımsal arazilerin miras yolu ile parçalanmanın önüne geçecek daha radikal bir düzenleme yapılmıştır (Küsek, 2014). Tablo 1'de ülkemizdeki tarım arazilerinin miras yoluyla parçalanmasını önleyici yasal düzenlemelerin kronolojisi verilmiştir.

Tablo 1: Tarımsal Arazilerde Miras ile Parçalanmayı Önleyici Yasal Düzenlemeler

\begin{tabular}{lc}
\hline Kanun/Yönetmelik/Talimat & $\begin{array}{c}\text { Resmi gazete } \\
\text { yayın tarihi }\end{array}$ \\
\hline Toprak Koruma ve Arazi Kullanımı Kanunu (No: 5403/ Madde 8) & 19.07 .2005 \\
Toprak Koruma ve Arazi Kullanımı Kanunu Uygulama Yönetmeliği (Madde & 15.12 .2005 \\
11) & \\
$\quad$ Toprak Koruma ve Arazi Kullanımı Kanununda Değişiklik Yapılması Hakkında & 15.05 .2014 \\
Kanun (No: 6537) & 31.12 .2014 \\
Tarımsal Arazilerin Mülkiyetinin Devrine İlişkin Yönetmelik & 27.06 .2014 \\
Toprak Koruma ve Arazi Kullanımı Kanunu Uygulama Talimatı & 03.02 .2015 \\
Tarımsal Arazilerin Mülkiyetinin Devrine İlişkin Uygulama Talimatı & 03.11 .2017 \\
Tarımsal Arazilerin Mülkiyetinin Devrine İlişkin Uygulama Talimatı & 13.04 .2018 \\
\hline Tarımsal Arazi Edindirme İş ve İşlemleri Hakkında Yönetmelik & \\
\hline
\end{tabular}

6537 sayılı Kanun'la 2014 yılında yürürlüğe giren değişikliklerin genel amac1, “toprağın korunması, gelişstirilmesi, tarım arazilerinin sinıflandırılması, asgari tarımsal arazi ve yeter gelirli tarımsal arazi büyüklüklerinin belirlenmesi ve bölünmelerinin önlenmesi, tarımsal arazi ve yeter gelirli tarımsal arazilerin çevre öncelikli sürdürülebilir kalkınma ilkesine uygun olarak planlı kullanımını sağlayacak" usul ve esasları belirlemektir. Kanunda "Asgari Tarımsal Arazi Büyüklüğ̈̈", "Yeter Gelirli Tarımsal Arazi Büyüklüğ̈̈” ve "Ekonomik Bütünlük” olmak üzere üç önemli kavram öne çıkmaktadır.

Asgari tarımsal arazi büyüklüğü, “...Bakanlıkça belirlenen en küçük tarımsal parsel büyüklü̈̆̈̈” olarak ifade edilerek daha alt parçalara bölünemeyecek sinırl ” ifade etmektedir.

Yeter gelirli tarımsal arazi büyüklüğü, “ bir ailenin geçimini sağlayacak şekilde gelir elde edilebilecek arazi büyüklügünü ifade etmekte olup, bölgesel farklıllklar dikkate alınarak bu büyüklük il ve ilçeler bazında sulu, kuru, dikili ve örtü altı araziler için büyüklükleri kanunun ekli listesinde verilmiştir".

Ekonomik bütünlük, "mülkiyeti aynı kişiye ait birden fazla tarımsal arazinin tarımsal üretim faaliyetine ekonomik bir değer katacak şekilde birbirine bağıml olarak işletildiği Bakanlıkça tespit edilen arazileri" ifade etmektedir.

6537 sayılı Kanun'un önemli kavramlarından biri olan ekonomik bütünlük kavramı 6537 sayılı Kanun'a eklenen 8/A maddesinde tanımlanmış olup, "yeterli gelirli tarımsal arazi büyüklüklerinin hesaplanmasında aynı kişiye ait ve Bakanlıkça aralarında ekonomik bütünlük bulunduğu tespit edilen tarım arazilerinin birlikte değerlendirileceği ve ekonomik bütünlüğe sahip olmayan kısımların Bakanlı̆̆ın izni ile satılabileceği” hükmene bağlanmıştır. Tarımsal Arazilerin Mülkiyetinin Devrine İlişkin 31.12.2014 tarihli Yönetmeliğin 7 maddesine göre; aynı kişiye ait tarımsal araziler arasındaki ekonomik bütünlük olup olmadığının tespiti aşağıdaki kriterlere göre belirlenmektedir:

a) "Örtü altı tarım arazilerinde bir dekar, dikili tarım arazilerinde beş dekar, sulu ve kuru tarım arazilerinde on dekarın altında olan tarım arazileri ekonomik bütünlük arz etmez”.

b) "Aynı kişiye ait sinırdaş olmayan tarım arazilerinin aralarındaki mesafe on km'den az ve örtü altı tarım arazilerinde bir dekar, dikili tarım arazilerinde beş dekar, sulu ve kuru 
tarım arazilerinde on dekarın üzerinde ise bu araziler arasında ekonomik bütünlük bulunduğu kabul edilir".

c) "Mülkiyeti aynı kişiye ait, sınırdaş olan tarımsal arazilerin ekonomik bütünlük teşkil ettiği kabul edilir".

d) "Aynı kişiye ait tarımsal arazilerden birinin veya birkaçının paylı olması durumunda kişinin tarım arazisi içindeki pay miktarı dikkate alınarak ekonomik bütünlük değerlendirmesi yapulır".

"Tarımsal arazilerin miras paylaşımına düzenleme getiren bu kanunda tarımsal arazi ve işletmenin mülkiyetinin devri esastır. Mülkiyet işlemleri ile ilgili sürecin mirasçıların isteğine bırakılmayarak, devir işlemlerinin kanunun yürürlüğe girdiği tarihten itibaren en geç bir yıl içinde tamamlanması öngörülmüştür. Miras kalan tarımsal arazi ve işletmenin mülkiyeti, mirasçılar arasında anlaşma sağlanması halinde; bir mirasçıya veya yeter gelirli tarımsal arazi büyüklüklerini karşılaması durumunda birden fazla mirasçıya, aile malları ortaklı̆̆ına, mirasçılarının tamamının miras payı oranında hissedarı oldukları Türk Ticaret Kanunu hükümlerine göre kuracakları limited şirkete veya Mirasa konu arazilerin tamamının üçüncü kişilere devrine karar verebileceklerdir. Ayrıca mirasçılar arasında anlaşma sağlanmaması veya yasal sürenin sona ermesi halinde Bakanlıkça dava açılması durumunda da ilgili mahkemece verilebilecek devir kararları kanunda belirlenmiştir (Resmi Gazete 2014)”.

Tarım Bakanlığı (Tarım Reformu Genel Müdürlüğü) 2017 yılı verilerine göre, Türkiye'de toplam 23,8 milyon hektar tarım arazisi üzerinde aktif kullanıcı sayısı ise 3 milyon iken bu arazilerin üzerinde 40 milyondan fazla hissedarın bulunduğu bildirilmektedir. Ülkemizde ortalama işletme büyüklüğü 6.1 ha, ortalama parsel büyüklüğü 10.9 da ve işletme başına düşen ortalama parsel adedi 5.4'tür. Ülkemizde 1961 yılından beri arazi toplulaştırma çalışması yürütülmekte ve hala yoğun bir şekilde devam etmektedir. Arazi toplulaştırması ile temel amaç bir işletmeye ait parçalı ve dağınık arazilerin mümkün olduğunca birleştirilmesidir. Ancak tarımsal arazilerin miras paylaşımında yasada geçen asgari tarımsal arazi büyüklüğü ve ekonomik bütünlük kavramları nedeniyle işletme sahiplerinin miras kanunundan etkilenmemek amacıyla arazi toplulaştırma çalışmaları ile parsellerini birleştirmeye yanaşmayacağı düşüncesi ortaya çıkmıştır. Bu çalışma ile "6537 sayılı Toprak Koruma ve Arazi Kullanımı Kanununda Değişiklik Yapılması Hakkında Kanun"dan önce arazi toplulaştırması gerçekleştirilen Karamürsel, Altınova, Karakışla köyleri ile kanundan sonra toplulaştırma çalışması yürütülen Yazılı ve Çiceközü mahallelerin de yeter gelirli işletme büyüklügü̈, asgari tarımsal arazi büyüklüğü ve ekonomik bütünlük kavramları yönünden analizi yapılmıştır.

\section{Materyal ve Yöntem}

\section{Materyal}

Bu çalışmada "6537 sayılı Toprak Koruma ve Arazi Kullanımı Kanununda Değişiklik Yapılması Hakkında Kanun"dan önce arazi toplulaştırması gerçekleştirilen Çankırı Kızılırmak İlçesi Karamürsel Köyü, Denizli Tavas İlçesi Altınova Köyü, Konya Karapınar İlçesi Karakışla Köyü ve kanundan sonra toplulaştırma çalışması gerçekleştirilen Bursa Yenişehir İlçesi Yazılı ve Çiçeközü mahallelerine ait toplulaştırma verileri kullanılmıştır.

Toplulaştırma çalışmalarına ait veriler ilgili kurumlardan alınmıştır. Yeni miras kanunu ile ilgili yasal durumu inceleyebilmek için ilgili miras ile ilgili kanunlar, yönetmelikler ve talimatlar ile bugüne kadar bu konuda yapılan bilimsel araştırmalardan yararlanılmıştır.

\section{Yöntem}

Bu çalışmada "6537 sayılı Toprak Koruma ve Arazi Kullanımı Kanunu”"nda yer alan "asgari tarımsal arazi büyüklüğü" ve "yeter gelirli tarımsal arazi büyüklüğü" ve "ekonomik bütünlük" 
kavramları incelenmiştir. Bu kavramların arazi toplulaştırma öncesi ve sonrası çalışma alanındaki değişimleri ortaya konmaya çalış1mıştır.

Asgari tarımsal arazi büyüklüğ̈̈, daha alt parçalara bölünemeyecek en küçük tarımsal parsel büyüklüğü sınırını ifade etmektedir. "Asgari tarımsal arazi büyüklükleri mutlak tarım arazileri ve özel ürün arazilerinde 20 dekar, dikili tarım arazilerinde 5 dekar ve örtü altı tarımı yapılan arazilerde ise 3 dekar olarak belirtilmiştir". Bu çalışmada yer alan arazi toplulaştırma alanları mutlak tarım arazisi olduğundan çalışmada dikkate alınan asgari tarımsal arazi büyüklüğü 20 dekardır.

Yeter gelirli tarımsal arazi büyüklükleri kanunun ekinde her il ve ilçe için verilmiş olup çalışma alanının kapsadığı ilçeler için Tablo 2'de verilmiştir.

Tablo 2: Çalışma Alanına Ait Yeter Gelirli Tarımsal Arazi Büyüklükleri

\begin{tabular}{llcccc}
\hline İl & İlçe & \multicolumn{4}{c}{ Yeter gelirli tarımsal arazi büyüklüğ̈̈̈(da) } \\
\cline { 3 - 6 } & & Sulu Arazi(da) & Kuru Arazi(da) & Dikili & Örtüaltı arazi(da) \\
& & & & Arazi(da) & \\
\hline Çankırı & Kizılırmak & 80 & 190 & 10 & 3 \\
Denizli & Tavas & 60 & 160 & 10 & 3 \\
Konya & Karapınar & 60 & 170 & 10 & 3 \\
Bursa & Yenişehir & 60 & 130 & 10 & 3 \\
\hline
\end{tabular}

Kanunda "Aynı kişiye ait sınırdaş olmayan araziler arası $10 \mathrm{~km}$ 'den daha az mesafe olan ve örtüaltı arazi 1 da, dikili arazi 5 da, ekili arazi 10 da ve üzerinde büyüklüğ̈̈ sahip alanlar da ekonomik bütünlük bulunduğu kabul edilmektedir”. Çalışma alanları ekili tarım arazisi olduğundan dolayı ekonomik bütünlük için 10 da kullanılmıştır.

$\mathrm{Bu}$ çalışmada da işletmelerin sahip olduğu araziler, asgari tarımsal arazi büyüklüğü, yeter gelirli tarımsal arazi büyüklüğü ve ekonomik bütünlük çerçevesinde değerlendirilmiştir.

\section{Araştırma Sonuçları}

Çalışma alanı ait verilerine göre köylere ait genel durum Tablo 3'te verilmiştir. Tablo 3'e göre Karamürsel'de 715, Altınova'da 1619, Karakışla 'da 224, Çiçeközü'nde 724 ve Yazılı'da 309 adet işletme bulunmaktadır. Arazi toplulaştırma alanları sırasıyla 8517 da, 30004 da, 17278 da, 4712 da ve 3030 da'dır. Ortalama işletme büyüklükleri sırasıyla 11.9 da, 18.5 da, 77.1 da, 6.5 da ve 9.8 da'dır. AT oranları 2014 yılından önce uygulanan projelerde $\% 46, \% 49, \% 10$ olarak bulunurken 2014 'den sonra uygulanan projelerde $\% 16$ ve \%7 bulunmuştur. Arslan ve Tunca(2013) Bafra ovasında yaptıkları çalışmada AT oranlarını \%55, \%58 ve \%22, Boztoprak ve Ark.(2015) Kayseri Pınarbaşında yaptıkları çalışmada \%35 olarak bulmuşlardır. AT oranları proje alanındaki işletme sayısı ve parsel sayısına göre değişim göstermekte olup, parsel sayısındaki azalmayı ifade etmektedir. En düşük AT oranı Yazılı' da elde edilmiş olup bunu Karakışla ve Çiçeközü izlemektedir. Karakışla'da ortalama işletme büyüklüğü ve ortalama parsel büyüklük değerleri oldukça yüksektir. Karakışla'da ortalama işletme büyüklügü ve sahip oldukları ortalama parsel alanları yeter gelirli işletme büyüklüğüne yakındır. 
Tablo 3: Çalışma Alanlarının Genel Durumu

\begin{tabular}{|c|c|c|c|c|c|c|c|c|}
\hline & \multirow{2}{*}{$\begin{array}{c}\text { İşletme } \\
\text { sayıs1 }\end{array}$} & \multirow{2}{*}{$\begin{array}{c}\text { Alan } \\
\text { (da) }\end{array}$} & \multirow{2}{*}{$\begin{array}{l}\text { Ortalama } \\
\text { işletme } \\
\text { büyüklüğü } \\
\text { (da) }\end{array}$} & \multicolumn{2}{|c|}{ AT Öncesi } & \multicolumn{2}{|c|}{ AT Sonrası } & \multirow{2}{*}{$\begin{array}{c}\mathrm{AT} \\
\text { Oranı(\%) }\end{array}$} \\
\hline & & & & $\begin{array}{r}\text { Parsel } \\
\text { sayıs1 }\end{array}$ & $\begin{array}{l}\text { Ortalama parsel } \\
\text { büyüklüğü (da) }\end{array}$ & $\begin{array}{l}\text { Parsel } \\
\text { sayıs1 }\end{array}$ & $\begin{array}{l}\text { Ortalama parsel } \\
\text { büyüklüğg̈ (da) }\end{array}$ & \\
\hline Karamürsel & 715 & 8517 & 11.9 & 584 & 14.6 & 316 & 27.0 & 46 \\
\hline Altınova & 1619 & 30004 & 18.5 & 3364 & 8.9 & 1707 & 17.6 & 49 \\
\hline Karakışla & 224 & 17278 & 77.1 & 379 & 45.6 & 342 & 50.5 & 10 \\
\hline Çiçeközü & 724 & 4712 & 6.5 & 1531 & 3.1 & 1289 & 3.7 & 16 \\
\hline Yaz1lı & 309 & 3030 & 9.8 & 802 & 3.8 & 748 & 4.1 & 7 \\
\hline
\end{tabular}

Çalıșma alanına giren köyler için yeter gelirli arazi büyüklüğü analiz edilmiștir (Tablo 4). Çalışma alanındaki köylerin ortalama işletme büyüklüğü analiz edildiğinde sadece Karakışla köyünün ortalama işletme büyüklüğü $(77.1 \mathrm{da})$ Karapınar ilçesi için belirlenen yeter gelirli arazi büyüklüğünden fazladır. Diğer köylerin ortalama işletme büyüklüğü kendi bölgeleri için belirlenen yeter gelirli arazi büyüklüğünün oldukça altında olduğu görülmektedir. Yeter gelirli arazi büyüklüğünden küçük işletme oranı Karamürsel'de \%99.2, Altınova'da \%94.6, Karakışla'da \%63.4, Çiçeközü'nde \%99.7 ve Yazıll'da \%98.7'dir. Yeter gelirli arazi büyüklügüne sahip işletme oranı Karakışla'da \%36.6 olup diğer köylerde bu oran oldukça düşüktür. Bu durumda yeni düzenlemeye göre bir işletmenin tarımsal arazilerinin mirasa konu olması durumunda, işletme arazileri yeter gelirli arazi büyüklügü altında kaldığından arazilerin tümü ya bir kişiye devrolacak ya da anlaşamama durumunda ise tümüyle 3. kişilere devri söz konusu olacaktır.

Tablo 4: Yeter Gelirli Arazi Büyüklüğü Analizi

\begin{tabular}{|c|c|c|c|c|c|c|c|}
\hline \multirow[b]{2}{*}{$\begin{array}{c}\text { Çalışma } \\
\text { alanı }\end{array}$} & \multirow{2}{*}{$\begin{array}{c}\text { Yeter } \\
\text { gelirli arazi } \\
\text { büyüklüğü } \\
\text { (da) }\end{array}$} & \multirow[b]{2}{*}{$\begin{array}{l}\text { Ort. işletme } \\
\text { büyüklüğü } \\
\quad \text { (da) }\end{array}$} & \multirow[b]{2}{*}{$\begin{array}{c}\text { İşletme } \\
\text { sayısı }\end{array}$} & \multicolumn{4}{|c|}{ Yeter gelirli arazi büyüklüğünden } \\
\hline & & & & $\begin{array}{l}\text { Küçük } \\
\text { işletme } \\
\text { sayısı }\end{array}$ & $\%$ & $\begin{array}{l}\text { Büyük } \\
\text { işletme } \\
\text { sayısı }\end{array}$ & $\%$ \\
\hline Karamürsel & 80 & 11.9 & 715 & 709 & 99.2 & 6 & 0.8 \\
\hline Altınova & 60 & 18.5 & 1619 & 1531 & 94.6 & 88 & 5.4 \\
\hline Karakışla & 60 & 77.1 & 224 & 142 & 63.4 & 82 & 36.6 \\
\hline Çiçeközü & 60 & 6.5 & 724 & 722 & 99.7 & 2 & 0.3 \\
\hline Yazılı & 60 & 9.8 & 309 & 305 & 98.7 & 4 & 1.3 \\
\hline
\end{tabular}

Daha alt parçalara bölünemeyecek en küçük tarımsal parsel büyüklüğü olarak ifade edilen asgari tarımsal arazi büyüklüğü, "mutlak tarım arazileri ve özel ürün arazilerinde 20 dekar" olarak belirlenmiştir. Çalışma alanında AT öncesi asgari arazi büyüklügünün altında bulunan parsellerin oranı Karamürsel'de \%82.4, Altınova'da \%90.6, Karakışla'da \%31.4, Çiçeközü’nde \%99.9, Yazılı'da \%99.5 iken, asgari arazi büyüklüğüne sahip parsel oranı sadece Karakışla köyünde \%68.6 olup diğer alanlarda \% 20'nin altındadır (Tablo 5). AT sonras1 parsellerin birleştirmesi sonucunda Karamürsel'de oluşan parsellerin \%50.6's1, Altınova'da \%27.6'sı, Karakışla'da \%75.4'ü asgari arazi büyüklük değerinin üzerine çıkmıştır. Miras yasasından sonra arazi toplulaştırma çalışmaları yürütülen Çiçeközü ve Yazılı' da parsellerin yaklaşık 99.5'i asgari arazi büyüklüğü altında kalmış ve asgari arazi büyüklügündeki parsel sayısında herhangi bir değişim gözlenmemiştir. AT çalışmalarının amacı işletmeye ait parselleri birleştirerek ortalama parsel büyüklüğünü arttırmaktır. 
En azından asgari arazi büyüklüğüne erişmesini sağlamak temel amaç olmalıdır. Asgari arazi büyüklügüne erişen parsellerin bu büyüklüğün altında bölünerek satılması yasalar ile engellenmiştir.

Tablo 5: Asgari Arazi Büyüklüğünün Analizi

\begin{tabular}{|c|c|c|c|c|c|c|c|c|c|c|}
\hline \multirow{3}{*}{ Çalışma Alanı } & \multicolumn{5}{|c|}{ AT Öncesi } & \multicolumn{5}{|c|}{ AT Sonrası } \\
\hline & \multicolumn{2}{|c|}{$<20 \mathrm{da}$} & \multicolumn{2}{|c|}{$20 \mathrm{da}=>$} & \multirow{2}{*}{$\begin{array}{c}\text { Toplam } \\
\text { Parsel } \\
\text { Sayısı }\end{array}$} & \multicolumn{2}{|c|}{$<20 \mathrm{da}$} & \multicolumn{2}{|c|}{$20 \mathrm{da}=>$} & \multirow{2}{*}{$\begin{array}{c}\text { Toplam } \\
\text { Parsel } \\
\text { Say1s1 }\end{array}$} \\
\hline & $\begin{array}{c}\text { Parsel } \\
\text { sayıs }\end{array}$ & $\%$ & $\begin{array}{l}\text { Parsel } \\
\text { Sayıs1 }\end{array}$ & $\%$ & & $\begin{array}{l}\text { Parsel } \\
\text { Sayis1 }\end{array}$ & $\%$ & $\begin{array}{l}\text { Parsel } \\
\text { Sayis1 }\end{array}$ & $\%$ & \\
\hline Karamürsel & 481 & 82.4 & 103 & 17.6 & 584 & 156 & 49.4 & 160 & 50.6 & 316 \\
\hline Altınova & 3049 & 90.6 & 315 & 9.4 & 3364 & 1236 & 72.4 & 471 & 27.6 & 1707 \\
\hline Karakışla & 119 & 31.4 & 260 & 68.6 & 379 & 84 & 24.6 & 258 & 75.4 & 342 \\
\hline Çiçeközü & 1529 & 99.9 & 2 & 0.1 & 1531 & 1287 & 99.8 & 2 & 0.2 & 1289 \\
\hline Yaz1lı & 798 & 99.5 & 4 & 0.5 & 802 & 744 & 99.5 & 4 & 0.5 & 748 \\
\hline
\end{tabular}

Çalışmada aynı zamanda ekonomik bütünlük değerlendirmesi yapılmıştır (Tablo 6). Çalışma alanlarındaki araziler ekili tarım arazisi olduğundan dolayı 10 da ve üzerinde büyüklüğü sahip ve birbirine $10 \mathrm{~km}$ 'den daha yakın olan alanlar ekonomik bütünlük arz etmektedir. Hisseli olan araziler de, kişinin pay oranı dikkate alınarak değerlendirme yapılmıştır. AT öncesi ekonomik bütünlüğe sahip işletme oranı Karamürsel'de \%19, Altınova'da \%36, Karakışla'da \%80, Çiçeközü’nde \%3.2 ve Yazılı'da \%11 olarak bulunmuştur. AT sonrasında bu oranlar Karamürsel'de \% 5.5 artarak \% 24'e, Altınova'da \% 6.8 artarak \% 43'e, Çiçeközü'nde \%1.1 artarak \% 4.3'e çıkmıştır. Karakışla'da ise \% 2.2 azalarak \% 77'ye düşmüştür. Yazılı'da da ekonomik bütünlüğe sahip işletme oranında herhangi bir değişiklik olmamıştır.

Tablo 6: Ekonomik Bütünlük Analizi

\begin{tabular}{|c|c|c|c|c|c|c|}
\hline \multirow{2}{*}{ Çalışma Alanı } & \multirow{2}{*}{$\begin{array}{l}\text { İșletme } \\
\text { sayıs1 }\end{array}$} & \multicolumn{2}{|c|}{$\begin{array}{l}\text { Ekonomik Bütünlüğe } \\
\text { Sahip Olmayan } \\
\text { İșletme }\end{array}$} & \multicolumn{2}{|c|}{$\begin{array}{l}\text { Ekonomik Bütünlüğe } \\
\text { Sahip İşletme }\end{array}$} & \multirow{2}{*}{$\begin{array}{c}\text { Ekonomik Bütünlüğe } \\
\text { Sahip İşletme Oranı } \\
\text { Farkı }\end{array}$} \\
\hline & & $\begin{array}{c}\text { AT } \\
\text { Öncesi } \\
(\%)\end{array}$ & $\begin{array}{l}\text { AT } \\
\text { Sonras1 } \\
(\%)\end{array}$ & $\begin{array}{c}\text { AT } \\
\text { Öncesi } \\
(\%)\end{array}$ & $\begin{array}{c}\text { AT } \\
\text { Sonras1 } \\
(\%)\end{array}$ & \\
\hline Karamürsel & 715 & 81 & 76 & 19 & 24 & 5.5 \\
\hline Altınova & 1619 & 64 & 57 & 36 & 43 & 6.8 \\
\hline Karakışla & 224 & 20 & 30 & 80 & 77 & -2.7 \\
\hline Çiçeközü & 724 & 97 & 96 & 3.2 & 4.3 & 1.1 \\
\hline Yazılı & 309 & 89 & 89 & 11 & 11 & 0 \\
\hline
\end{tabular}

Çalışma da 5 farklı alanda yapılmış AT çalışmaları incelenmiş ve bu çalışma alanlarındaki arazilerin mirasa konu olması durumunda karşılaşılabilecek durum ortaya konmaya çalışılmıştır. Çalışma alanları yeter gelirli arazi büyüklüğü açısından irdelendiğinde Konya Karapınar ilçesi içinde bulunan Karakışla köyünde ki işletmelerin \%36.6's1 yeter gelirli arazi büyüklüğünün üzerinde iken diğer alanlarda bu değer \%0.3 ile \%5.4 arasında kalmıştır. Konya ili genelinde ortalama işletme büyüklügü 132.3 da, ortalama parsel büyüklüğü 35.4 da ile ülkemizde işletme ve parsel büyüklüğü en fazla olan 5 il arasında yer almaktadır(TÜ̈IK 2001). Çalışma alanlarındaki işletme sayısı AT öncesi ve sonrası değişmediği için yeter gelirli arazi büyüklüğüne mevcut durumda yapılan AT çalışmalarının olumlu ya da olumsuz bir etkisi yoktur. Bu kapsamda AT çalışmalarının içeriğinin zenginleştirilerek AT çalışmaları sırasında işletme büyüklüğünü arttırmaya yönelik çalışmalar yapılmas1 gerekmektedir. 
6537 sayılı kanunda asgari tarımsal arazi büyüklükleri mutlak tarım arazilerinde 20 dekar olarak belirtilmiş olup bu değer göz önüne alınarak incelendiğinde 6537 sayılı kanundan önce toplulaştırması gerçekleştirilen Karamürsel ve Altınova da asgari arazi büyüklüğüne sahip parsel sayısında artış, Karakışla da asgari arazi büyüklüğündeki parsel sayısında azalma olduğu bulunmuştur. Karakışla'da ki asgari arazi büyüklüğündeki parsel sayısında azalmanın nedeni hisseli parsellerdeki hisse ayırma işlemlerinden dolayı oluşmuştur. 6537 sayılı kanundan sonra toplulaştırması gerçekleştirilen Çiçeközü ve Yazılı'da asgari arazi büyüklüğüne sahip parsel sayısında değişiklik bulunmamıştır. AT çalışmaların da temel amaç işletmelerin sahip olduğu parselleri mümkün olduğunca birleştirerek parsel büyüklüklerini arttırmak olmalıdır. AT ile ilgili yasal düzenlemeler bu birleştirme ile ilgili herhangi bir öngörüde bulunmamaktadır. Yasa ile belirlenmiş asgari tarımsal arazi büyüklüğü yeni oluşturulacak parsel büyüklüklerinde de hedef olmalıdır. Bu konuda ilgili yasa ve yönetmeliklere parsel birleştirmesini öngören koşullar konulmalidir.

Çalışmada işletmeler ekonomik bütünlük açısından incelendiğinde Konya Karapınar Karakışla'da ekonomik bütünlüğe sahip işletme sayısında azalma görülürken Karamürsel ve Altınova'da sayısında artış belirlenmiştir. Kanundan sonra arazi toplulaştırması gerçekleştirilen Çiçeközü ve Yazılı'da ekonomik bütünlüğe sahip işletme sayısında belirgin bir artış gözlenmemiştir. Tarımsal arazilerin bölünmesini ve parçalanmasını engellemek amacıyla çıkarılan 6537 sayılı kanunun etkin olabilmesi için tarımsal işletmelerin ekonomik bütünlük arzetmesi gerekmektedir. Tarımsal arazilerin mülkiyetinin devrine ilişkin yönetmeliğin (31.12.2014 tarihli) 8. maddesinin C bendinde "Aynı kişiye ait birden fazla tarımsal arazi olması halinde, 7. madde hükümlerine göre yapılan ekonomik bütünlük değerlendirmesi sonrasında tarımsal arazilerin ekonomik bütünlüğe haiz olmayan kisımlarınin devrine izin verilebilir" ifadesi bulunmaktadır. $\mathrm{Bu}$ durum bir tarımsal işletmenin 10 da'dan daha küçük parselleri varsa bu parseller ekonomik bütünlük değerlendirmesi sırasında ekonomik bütünlük arz etmeyeceği için işletme sahibi bu arazileri diğer arazilerinden bağımsız olarak satabilecektir. 30 Nisan 2014 yılında; "toprağın korunması, geliştirilmesi, tarım arazilerinin sınfflandırılması, asgari tarımsal arazi ve yeter gelirli tarımsal arazi büyüklüklerinin belirlenmesi ve bölünmelerinin önlenmesi, tarımsal arazi ve yeter gelirli tarımsal arazilerin çevre öncelikli sürdürülebilir kalkınma ilkesine uygun olarak planlı kullanımını sağlamak" amaciyla çıkarılan 6537 sayılı kanunun bu bağlamda değerlendirildiğinde gelecekte arazi toplulaştırma projelerinin amacı dışına çıkmasına neden olacağı düşünülmektedir. Arazi toplulaştırması ile birleştirilen ve 10 da üzerinde olan parsellerini bu yasa nedeniyle satamayacaklarını öğrenen işletme sahipleri küçük parsellerini birleştirmek istemeyeceklerdir. Mevcut AT yasalarında bunu engelleyen bir düzenleme bulunmamaktadır. Zaten ülke genelinde çokta yüksek olmayan AT oranları, işletmelerin yasanın bilincine varması ile daha da düşecektir. Bu bağlamda AT ile ilgi yasa ve yönetmeliklerde yeniden düzenleme ile birlikte yeni oluşacak parsellerin, işletme büyüklügü yeterli ise ekonomik bütünlük oluşturacak şekilde düzenlenmesi zorunluluğu getirilmelidir. Daha sonraki aşamalarda ise işletme büyüklüklerini yeter gelirli işletme büyüklüğüne çıartacak ek önlemler alınmalıdır. Bu kapsamda 13 Nisan 2018 tarihinde Tarımsal arazi edindirme iş ve işlemleri hakkında yönetmeliği çıkartılmıştır. Yönetmeliğin 9. Maddesi toplulaştırma alanlarında arazi edindirme konularını içermekte olup, arazi toplulaştırma alanlarında yeni parsel planlarının tanziminden önce; alım, satım, kiralama, hisseliliğin azaltılması, mülkiyetten kaynaklı ihtilafların giderilmesi, ortakçılık ve yarıcılık gibi işlemleri konu almaktadır. Ancak bu konu ile ilgili yasal düzenleme yapılmış olmasına rağmen henüz fiili olarak hayata geçmemiştir. Tarımsal işletme büyüklüklerin arttırılması amacıyla bu yönetmeliğin de bir an önce hayata geçirilerek, kırsal alanda yaşamayan, tarımdan kopmuş işletme arazilerinin tarımla uğraşan işletmelere devrini/kiralanmasını sağlayacak çalışmaların AT ile birlikte yapılması sağlanmalıdır.

Tarım arazilerinin miras yolu ile bölünmesi ülkemiz tarımındaki en büyük sorunlardan birisidir. Bu sorun her geçen gün artmakta olup, yapılan kanunsal değişiklikler ile sonunun çözülmesi 
amaçlanmaktadır. Ancak tarım arazilerindeki miras ya da farklı nedenlerle meydana gelen parçalı dağınık ve küçülmüş yapının düzeltilmesi ve yeni miras düzenlemesi ile ortaya çıkabilecek yeni mülkiyet sorunlarının çözümü ilgili bakanlıklara daha da büyük bir iş yükü getirecektir. Ortaya çıkacak bu iş yükünü karşılamak ve yeni miras kanunu hayata geçirebilmek adına yeniden yapılanmalara ihtiyaç bulunmaktadır. Kanun uygulamalarında karşılaşılan sorunların çözümü amacıyla konu ile ilgili bilimsel çalışmalar gerçekleştirilmelidir.

\section{Kaynakça}

Akkaya Aslan, S.T., Gündoğdu, K.S., Yaslığlu, E., Kirmikil, M, ve Arıcı I. (2007). Personal, physical and socioeconomic factors affecting farmers' adoption of land consolidation. Span. J. Agric. Res. 5 (2), 204-213.

Arıcı, I. ve Akkaya Aslan, S.T. (2014). Arazi Toplulaştırması Planlama ve Projelemesi. Dora pp. 237, ISBN: 978-605-4798-49-0. (in Turkish).

Arslan H., Tunca, E. (2013). Arazi Toplulaştırmasının Sulama Projelerinin Performası Üzerine Etkileri.Anadolu Tarım Bilim. Derg., 2013,28(3):126-133

Bentley, W. (1987). Economic and ecological approaches to land fragmentation: in defence of a much-maligned phenomenon. Annu. Rev. Anthropol. 16 (3), 46-57.

Boztoprak, T., Demir, O., Çoruhlu, Y.E., Nişancı, R. (2015). Arazi toplulaştırmasının tarımsal işletmelere etkilerinin araştırılması. Selçuk Üniversitesi Mühendislik, Bilim ve Teknoloji Dergisi, 3(3), 1-11.

Colombo, S., Perujo-Villanueva, M. (2019). A practical method for the ex-ante evaluation of land consolidation initiatives: Fully connected parcels with the same value. Land Use Policy Volume 81, Pages 463-471.

Crecente, R., Alvarez C., Fra, U. (2002). Economic, social and environmental impact of land consolidation in Galicia. Land Use Policy, 19(2), 135-147.

Demetriou, D. (2014). The Development of an Integrated Planning and Decision Support System (IPDSS) for Land Consolidation. Zug: Springer International Publishing Switzerland, pp. 340.

Derlich, F. (2002). Land consolidation: A key for sustainable development French experience. In: Proceedings of the XXII International FIG Congress, 19-26 April, 2002, Washington, D.C., USA.

Janus, J., Mika, M., Leń, P., Siejka M., Taszakowski, J. (2016). A new approach to calculate the land fragmentation indicators taking into account the adjacent plots. Surv. Rev., 50 (358), 1-7.

Jha, R., Nagarajan H.K., Prasanna, S. (2005). Land Fragmentation and its Implications for Productivity: Evidence from Southern India. ASARC Working Paper 2005/01, Australia South Asia Research Centre, RSPAS. Division of Economics, Australian National University.

Küsek, G. (2014). Türkiye'de Arazi Toplulaştırmasının Yasal Durumu ve Tarihsel Gelişimi. Ç.Ü.Z.F. Dergisi, 29 (1), $1-6$.

Kavasoğlu, İ.İ., Sayın, C. (2016).Tarımda Yeni Miras Kanunu Ve Olası Sonuçları, XII. Ulusal Tarım Ekonomisi Kongresi 25-26 Mayıs, Süleyman Demirel Üniversitesi Tarım Ekonomisi Bölümü. 
Yeni Miras Kanununun Arazi Toplulaştırmasına Olası Etkilerinin İncelenmesi Üzerine...

King, R., Burton, S. (1982). Land fragmentation: notes on a fundamental rural spatial problem. Prog. Hum. Geogr. 6 (4), 475-494.

Lerman, Z.( 2005). Farm fragmentation and productivity: Evidence from Georgia. Discussion Paper No. 8.05. Department of Agricultural Economics and Management, The Hebrew University of Jerusalem, $10 \mathrm{p}$.

Luo, W., Timothy, D.J. (2017). An assessment of farmers' satisfaction with land consolidation performance in China. Land Use Policy, 61, 501-510.

Niroula, G.S., Thapa, G.B. (2005). Impacts and causes of land fragmentation and lessons learned from land consolidation in Asia. Land Use Policy, 22 (4), 358-372.

Nguyen, T., Cheng, E.J., Findlay, C. (1996). Land fragmentation and farm productivity in China in the 1990s. China Economic Review, 7(2), 169-180.

Ntihinyurwa, P.D., Vries, W.T., Chigbu U.E., Dukwiyimpuhwe, P.A.(2019). The positive impacts of farm land fragmentation in Rwanda. Land Use Policy, 81, 565-58.

Özçelik, Ş.B. (2015). 5403 Sayılı Toprak Koruma Ve Arazi Kullanımı Kanunu'nda 6537 Sayılı Kanun'la Yapılan Değişiklikler Ve Değerlendirilmesi, Gazi Üniversitesi Hukuk Fakültesi Dergisi C. XIX,„87-110.

Resmi Gazete (2014). Toprak Koruma ve Arazi Kullanımı Kanununda Değişiklik Yapılmasına Hakkında Kanun (No:6537), Tarih:05.05.2014, Say1:29001, Ankara

Sayın C., Altunkaya, M., Taşçığlu, Y.O,. Kavasoğlu, İ.(2017).Türkiye'de toprak parçalanması ve miras hukuku. Mediterranean Agricultural Sciences, 30(3), 213-218.

Sayın C. (2018). Tarım Hukuku Dersi Notları, Akdeniz Üniversitesi Ziraat Fakültesi Tarım Ekonomisi Bölümü, Antalya.

Shuhao, T. (2005). Land fragmentation and rice production: a case study of small farms in Jiangxi Province. P.R. China, PhD thesis, Wageningen University.

Sklenicka, P. (2006). Applying evaluation criteria for the land consolidation effect to three contrasting study areas in the Czech Republic. Land Use Policy, 23(4), 502-510.

Tan, S., Heerink N., Qu, F. (2006). Land fragmentation and its driving forces in China. Land Use Policy, 23 (3), 272-285.

Thomas, J. ( 2004). Modern land consolidation: recent trends on land consolidation in Germany. In: Proceedings of Symposium on Modern Land Consolidation, 10-11 September 2004, Volvic (Clermont-Ferrand), France.

Thomas, J. (2006). Property rights, and fragmentation and the emerging structure of agriculture in Central and Eastern European countries. Journal of Agricultural and Development Economics, 3(2), 225-275.

Tüik, 2001. Genel Tarım Sayımı, Türkiye İstatistik Kurumu, Ankara.

Van Dijk, T. (2003). Scenarios of Central European land fragmentation. Land Use Policy, 20, 149 158.

Van Dijk, T. (2007). Complications for traditional land consolidation in Central Europe. Geoforum, $38,505-511$.

Van Hung, P., MacAulay G.T., Marsh, S.P. (2007). The economics of land fragmentation in the north of Vietnam. Aust. J. Agric. Resour. Econ., 51 (2), 195-211. 
Wan, G.H., Cheng, E.J. (2001). Effects of land fragmentation and returns to scale in the Chinese farming sector. Applied Economics, 33(2), 183-194.

Yaslığlu, E., Arıcı, I., Kuşçu, H., Gündoğdu, K.S., Akkaya Aslan S.T., Kirmikil, M.(2008). Adoption factors of irrigation systems whose projects are synchronized with land consolidation. Kuwait J. Sci. Eng., 35 (2A), 1-10.

Yaslıoğlu, E., Akkaya Aslan, S.T., Kirmikil, M., Gündoğdu K.S., Arıcı, I. (2009). Changes in farm management and agricultural activities and their effect on farmers' satisfaction from land consolidation: The case of Bursa-Karacabey, Turkey. European Planning Studies, 17(2), 327-340. 